\title{
Cardiac syncope due to transient coronary artery occlusion: the role of percutaneous angioplasty
}

\author{
Steven Burn, Richard Schilling, Gerald C Kaye
}

\begin{abstract}
Summary
A case of cardiac syncope is presented, associated with single vessel coronary disease. The mechanism of the syncope would appear to be a ventricular arrhythmia with transmural myocardial ischaemia due to transient occlusion of the diseased coronary artery. The symptoms and electrocardiographic abnormalities were reproduced and subsequently abolished by percutaneous coronary angioplasty.
\end{abstract}

Keywords: angina; ventricular tachycardia; angioplasty; syncope

In 1959, Myron Prinzmetal described the syndrome of variant angina pectoris with associated electrocardiographic ST elevation, which now bears his name. ${ }^{1}$ This syndrome has been rarely associated with cardiac arrhythmias, including ventricular tachycardia, ventricular fibrillation and sudden cardiac death. We present a case of syncope due to a presumed ventricular arrhythmia with preceding ST elevation due to transient, possibly vasospastic, occlusion in an atheromatous coronary artery.

\section{Case history}

A 56-year-old man presented following an episode of syncope. He had been riding his bicycle when he became dizzy and then abruptly lost consciousness. He recollected a similar episode two weeks beforehand. There was no history of chest pain, self-injury, incontinence or recent head injury. There was no significant medical history or family history and he was on no medication. He smoked 20 cigarettes a day and drank 20 units of alcohol per week.

On admission, he was conscious and orientated. Blood pressure was $155 / 100 \mathrm{mmHg}$ with no postural drop; pulse was 84 beats/min and regular. Examination of the respiratory, cardiovascular, and central nervous systems were normal.

A diagnosis of exertional syncope of uncertain cause was made. Admission full blood count and biochemistry were normal. His electrocardiogram (ECG) showed sinus rhythm with minor $\mathrm{T}$ wave flattening in V5 and V6. The QT interval was normal. A subsequent electroencephalogram (EEG) and computed tomography brain scan were normal. A 24hour ambulatory ECG was performed. This revealed frequent ventricular ectopy with apparent runs of a broad complex tachycardia with a varying morphology (figure 1). A diagnosis of a polymorphic ventricular tachycardia (VT) was made. Subsequent echocardiography was normal. Serum magnesium was mildly reduced at $0.62 \mathrm{mmol} / 1$ (normal range $0.7-1.0$ ). He was discharged on sotalol, $80 \mathrm{mg}$ bid, and aspirin, $300 \mathrm{mg}$ od, with plans for outpatient review.

He was re-admitted 21 days later with a further episode of syncope whilst walking. Physical examination was again normal. Serial ECGs and cardiac enzymes were normal. A thallium perfusion study revealed a mild, fixed, septal and apical defect. Continuous ECG monitoring revealed repeated episodes of apparent non-sustained VT. These persisted despite intravenous amiodarone and magnesium sulphate. An electrophysiological opinion was sought. On review of the monitor strips it became apparent that spontaneous episodes of ST segment elevation and QRS widening were occurring, with an associated sinus tachycardia. This preceded the observed ventricular ectopy and lead to the erroneous impression of a polymorphic ventricular tachycardia (figure 2). A diagnosis of intermittent coronary artery occlusion was made, probably due to vasospasm, with secondary syncopal VT.

At coronary angiography a $50 \%$ proximal and $80 \%$ mid-stenosis of the left anterior descending coronary artery were noted, with normal right and circumflex arteries. The stenoses persisted after intracoronary nitrates. Percutaneous coronary angioplasty was performed to both stenoses with angiographically good results. Within $30 \mathrm{~s}$ of balloon inflation the QRS complexes widened, with ST segment elevation and sinus tachycardia; frequent ventricular ectopics were observed. These changes resolved on balloon deflation.

Following the angioplasty no arrhythmias were monitored. An exercise ECG was normal

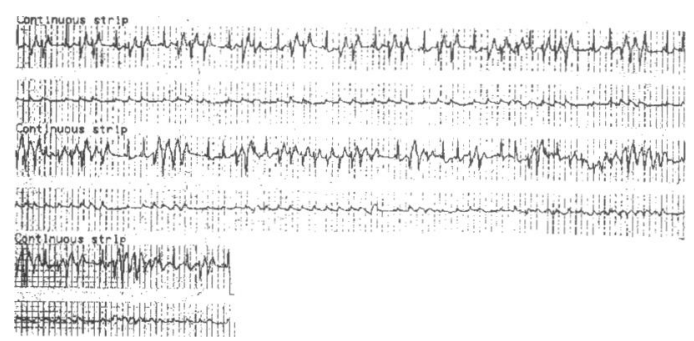

Figure 1 24-Hour ECG showing ectopics and apparent broad complex rhythm. Note the marked ST elevation in broad complex runs 


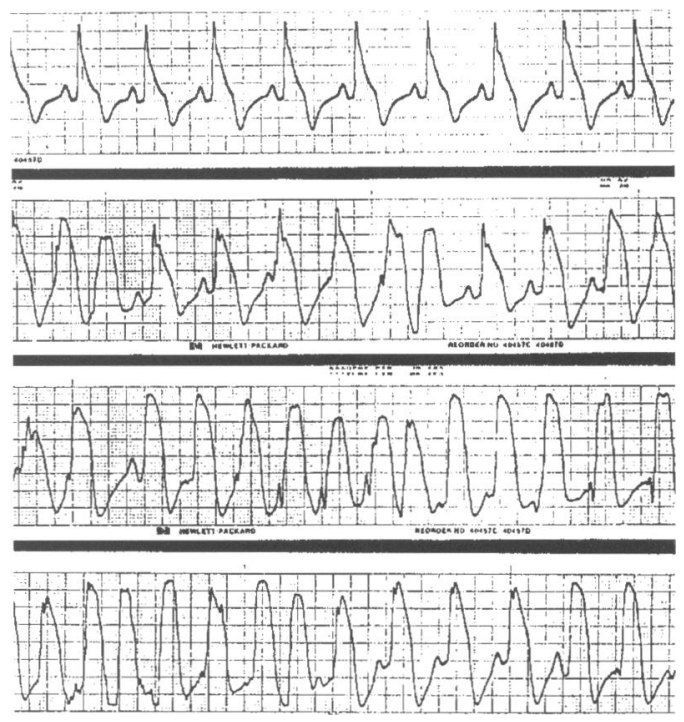

Figure 2 Monitor strip showing spontaneous ST elevation and ventricular ectopy

at $9 \min 46 \mathrm{~s}$ on a Bruce protocol. On review 43 days after angioplasty the patient remained well with no further episodes of syncope and a normal 24-hour ECG. He was maintained on verapamil and aspirin.

\section{Discussion}

Variant angina has been demonstrated to be due to vasospasm of an epicardial coronary artery with transient coronary occlusion. ${ }^{2}$ This leads to transmural ischaemia with ST segment elevation on the surface ECG. Severe coronary atherosclerosis is present in approximately two-thirds of patients, with spasm usually occurring within $1 \mathrm{~cm}$ of the organic stenoses. Although classically symptoms and ECG changes occur at rest, they can also occur during or after exertion. ${ }^{2}$ Ventricular ectopy can be associated with episodes of ST elevation, along with complex ventricular arrhythmias. Such patients are at increased risk of sudden death. ${ }^{3}$

There is strong evidence linking ischaemia to ventricular arrhythmias and $94 \%$ of patients resuscitated from cardiac arrest have coronary lesions of $70 \%$ or more. ${ }^{4}$ The mechanism of

1 Prinzmetal M, Kennamer R, Merliss R, et al. A variant form of angina pectoris. Am $\mathcal{f}$ Med 1959;27:375.

2 Rutherford JD, Braunwald E. Variant angina pectoris. In: Braunwald E, ed. Heart disease. WB Saunders Company, 1992; pp 1342-5.

3 Miller DD, Waters DD, Szlachcic MD, Theroux P. Clinical characteristics associated with sudden death in patients with variant angina. Circulation 1982;66:588-92.

4 Mundth ED, Buckley MJ, De Sanctis RW, Daggett WM, Austen WG. Surgical treatment of ventricular irritability. $\mathscr{f}$ Thorac Cardiovasc Surg 1973;66:943-51.

5 Wit AL, Bigger JT Jr. Possible electrophysiological mechanisms for lethal arrhythmias accompanying myocardial nisms for lethal arrhythmias accompanying myocarc

6 Wolfe CL, Nibley C, Bhandari A, Chatterjee K, Scheinman $\mathrm{M}$. Polymorphous ventricular tachycardia associated with acute myocardial infarction. Circulation 1991;84:1534-51.

\section{Summary points}

- syncope on exertion is usually due to a cardiovascular cause

- coronary vasospasm can present relatively 'silently' with ventricular arrhthymias

- ventricular arrhthymias in association with variant angina carry a poor prognosis

- in selected cases, coronary revascularisation can abolish ventricular arrhythmias

these arrhythmias appears to be re-entry around areas of functional block caused by prolonged refractoriness of ischaemic tissue. ${ }^{5}$ Polymorphic VT is generally felt to be related to functional rather than anatomical block and thus ischaemia rather than infarct scar, $^{6}$ whereas monomorphic VT is considered to be related to anatomical block related to infarct tissue.

Revascularisation can be useful when VT is related to ischaemia ${ }^{7}$ and previous studies have suggested that monomorphic VT can be abolished by revascularisation with coronary artery bypass grafting. ${ }^{8}$ Abolishment of recurrent ischaemic VT with percutaneous angioplasty has been demonstrated before but the nature of the tachycardia was not defined and documentation of ischaemia causing the arrhythmia was not demonstrated clearly. ${ }^{910}$ The gradual widening of the QRS complexes during inflation of the angioplasty balloon with a sinus tachycardia and ST elevation with complete regression of these changes on balloon deflation exactly mirrored the ECG changes seen spontaneously at rest. The spontaneous episodes of coronary occlusion in this patient could have been due to platelet thrombus at the site of atheroma; however, we feel that vasospasm was a more likely aetiology, given the clinical picture, concomitant use of aspirin and ECG changes. Our case demonstrates that acute transmural ischaemia, probably related to coronary vasospasm, can be associated with syncope; this may be successfully treated with revascularisation. Percutaneous angioplasty is both safe and effective in achieving this.

7 O'Rourke R. Role of myocardial revascularisation in sudden death. Circulation 1992;85(suppl 1):112-7.

8 Berntsen RF, Gunnes P, Lie M, Rasmussen K. Surgical revascularisation in the treatment of ventricular tachycardia and fibrillation exposed by exercise-induced ischaemia. Eur Heart $\mathcal{f} 1993 ; 14: 1297-303$.

9 Molajo AO, Summers GD, Bennett DH. Effect of percutaneous transluminal coronary angioplasty on arrhythmias complicating angina. Br Heart $\mathcal{f} 1985 ; 54: 375-7$

10 Hilton TC, Aguirre F, Greenwalt T, Janosik DL, Kern MJ. Successful treatment of complex ventricular arrhythmias with percutaneous transluminal coronary angioplasty. $\mathrm{Am}$ Heart $\mathcal{F}$ 1991;122:230-1. 